\title{
Lichen Striatus
}

\author{
Alexander K. C. Leung ${ }^{1 *}$ and Benjamin Barankin ${ }^{2}$ \\ ${ }^{1}$ Clinical Professor of Pediatrics, University of Calgary, Pediatric Consultant, Alberta Children's Hospital, Calgary, Alberta, Canada \\ ${ }^{2}$ Dermatologist, Medical Director and Founder, Toronto Dermatology Centre, Toronto, Ontario, Canada
}

\begin{abstract}
Lichen striatus is a benign, acquired, T-cell mediated dermatosis characterized by a blaschko linear inflammatory papular eruption. The condition is seen primarily in children. The onset is usually abrupt. The eruption consists initially of discrete, flesh-colored or erythematous, flat-topped papules, 1 to 3 mm in diameter. Papules often coalesce to form a hyperpigmented continuous or interrupted linear band. Although lichen striatus may involve any part of the body, the arms and legs are most commonly affected. Typically, the lesion is solitary, unilateral, and follows Blaschko lines. The lesion is usually asymptomatic and nonpruritic. Lichen striatus is a self-limited condition that often resolves within 1 year. Because of the benign nature of the condition, treatment is usually not necessary apart from reassurance. For those patients who would like to have therapy for cosmetic reasons, a topical corticosteroid or a topical immunomodulator (tacrolimus or pimecrolimus) is the treatment of choice.
\end{abstract}

\section{Introduction}

Lichen striatus is a benign, acquired, asymptomatic, self-limited $\mathrm{T}$-cell mediated dermatosis [1,2]. It is characterized by a blaschko linear inflammatory papular eruption and is seen primarily in children $[3,4]$.

\section{Epidemiology}

Lichen striatus is a relatively uncommon condition that typically affects children between ages 5 and 15 years $[3,5]$. It has occasionally been described in infants and adults [1]. The female to male ratio is approximately 2:1 [2]. There is no known racial variation in incidence [2]. The condition is more common in the spring and summer [6]. Approximately 60 to $85 \%$ of patients with lichen striatus have a personal or family history of asthma, atopic dermatitis, or allergic rhinitis $[3,4]$.

Lichen striatus usually occurs sporadically [4]. Simultaneous familial occurrences have rarely been described [7-9]. Infection, hypersensitivity reactions, vaccines, medications, and trauma are possible predisposing factors $[3,6,10,11]$. It is possible that a cross reactivity develops between the aforementioned antigens (e.g., vaccines, medications) and shared epitopes on keratinocytes which acts as a triggering factor [12].

\section{Pathogenesis}

The exact pathogenesis is not known. Many authors believe that it is a form of cutaneous mosaicism in which an abnormal clone of keratinocytes arises due to a post-zygotic somatic mutation $[6,13]$. In this situation, the body tolerates the aberrant clone until an acquired event such as a viral infection or trauma, which results in a T-cell mediated inflammatory reaction [13]. There is also a genetic predisposition to this disorder [8].

\section{Histopathology}

A superficial perivascular lymphocytic and histiocytic infiltrate and a lichenoid infiltrate in the papillary dermis with the presence of an inflammatory infiltrate surrounding hair follicles and eccrine glands are characteristic $[4,14,15]$. Focally, in the papillary dermis, the infiltrate may have a band-like distribution with extension into the lower portion of epidermis. Focal spongiosis, necrotic keratinocytes, exocytosis, patchy hyperkeratosis, parakeratosis, and dyskeratosis may also be noted $[3,9,15]$.

\section{Clinical manifestations}

Lichen striatus is characterized by an abrupt onset of discrete, fleshcolored, pink, tan, or erythematous, flat-topped papules, 1 to $3 \mathrm{~mm}$ in diameter [1,9]. Papules often coalesce to form a hyperpigmented continuous or interrupted linear band over a few weeks (Figure 1) $[4,9,16]$. The linear band may develop a curved appearance as it follows Blaschko lines (the cutaneous lines of epidermal cell migration during embryonic development) [4]. Sometimes, two bands that parallel each other may be observed [15]. In dark-skinned persons, the lesions may be hypopigmented (lichen striatus albus) [4]. Although lichen striatus may involve any part of the body, the arms and legs are most commonly affected, followed by the trunk, buttocks, face, and nails $[1,3,14]$. Rarely, the lesion is seen on the penis $[1,4]$.

Typically, the lesion is solitary and unilateral [16]. V-shaped lines on the mid-back may be bilateral [15]. Rarely, atypical forms with multiple and bilateral lesions have been described [17]. Typically, the lesion starts on a proximal extremity and extends distally. The band is usually $2 \mathrm{~mm}$ to $2 \mathrm{~cm}$ in width; the length can vary from a few $\mathrm{cm}$ to, occasionally, the entire length of an extremity [16].

The lesion is usually asymptomatic [4]. Pruritus is uncommon,

Correspondence to: Dr. Alexander K.C. Leung, Clinical Professor of Pediatrics, University of Calgary, Pediatric Consultant, Alberta Children's Hospital, \#200, $233-16^{\text {th }}$ Avenue NW, Calgary, Alberta, Canada T2M 0H5, Tel: (403) 230-3322; E-mail: aleung@ucalgary.ca

Key words: Lichen striatus, linear, flat-topped papules, asymptomatic, self-limited Received: February 04, 2015; Accepted: February 14, 2015; Published: February 19,2015 


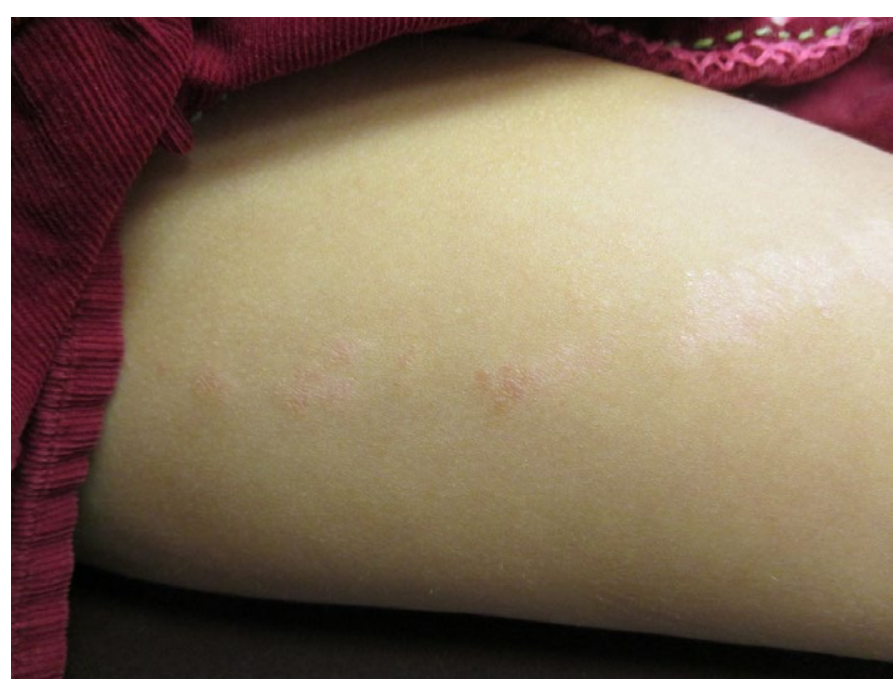

Figure 1. Linear erythematous, lichenoid coalescing papules on the lateral aspect of the right thigh.

except in those patients with atopy [3]. However, when the onset occurs in adulthood, the lesions may be widespread and pruritic [18].

Rarely, onychodystrophy may occur, especially when the eruption involves the posterior nail fold and matrix [5]. Nail changes may include nail pitting, longitudinal ridging, splitting, fraying, onycholysis, punctate or striate leukonychia, hyperkeratosis of the nail bed, overcurvature of the nail plate, and thinning or thickening of the nail plate [3,7]. Very rarely, the nails may fall off completely [7]. Usually, only the lateral or medial portion of the nail plate of only one nail is affected [3]. Nail involvement may present before, after, or concurrent with the skin lesion $[5,7]$.

\section{Diagnosis}

The diagnosis is usually made clinically based on the characteristic appearance of skin lesions and a pattern of distribution that follows the lines of Blaschko. Further diagnostic work-up is usually not necessary. If the diagnosis is in doubt, a biopsy of the lesion should be considered for histopathologic confirmation or referral to a dermatologist.

\section{Differential diagnosis}

The differential diagnosis includes lichen planus, linear psoriasis, linear epidermal nevus, inflammatory linear verrucous epidermal nevus, allergic dermatitis, atopic dermatitis, linear porokeratosis, and linear Darier's disease. Both lichen planus and linear psoriasis are usually associated with typical individual lesions elsewhere on the body. In addition, the lesions of lichen planus are usually pruritic, tend to be larger, violaceous, and may be hypertrophic [5]. The lesion of linear epidermal nevus usually appears in early infancy and does not regress [5]. With time, the lesion becomes more keratotic, warty, and hyperpigmented than that of lichen striatus. The lesion of inflammatory linear verrucous nevus tends to be extensive and is markedly pruritic [5]. It does not regress spontaneously [3]. The lesions of allergic dermatitis and atopic dermatitis are typically pruritic. Linear porokeratosis is characterized by single or multiple plaques with hyperkeratotic peripheral rims linearly and unilaterally distributed on one extremity. The hyperkeratotic border is often prominent. Linear Darier's disease is a mosaic cutaneous form of Darier's disease characterized by unilateral skin lesions conforming to linear, zosteriform or localized patterns located on Blaschko's lines. The lesions consist of greasy discrete, flat- topped, hyperkeratotic papules and plaques that occur in seborrheic areas. Lesions are itchy, yellow brown, brown or skin-colored, and feel like coarse sandpaper.

\section{Complications}

Lichen striatus can be cosmetically unsightly and can cause distress to patients. In addition, postinflammatory hyperpigmentation and hypopigmentation may occur especially in dark-skinned individuals [7]. The discoloration may last for months to years [7].

\section{Prognosis}

Lichen striatus is a self-limited condition that often resolves within 1 year $[8,16]$. When associated with onychodystrophy, the lesion tends to persist longer [5]. Relapses are rare [3].

\section{Management}

Because of the benign and self-limited nature of the condition, treatment is usually not necessary apart from reassurance. For those patients who would like to have therapy for cosmetic reasons, a topical corticosteroid or a topical immunomodulator (tacrolimus or pimecrolimus) is the treatment of choice because it may hasten resolution of the lesion [18].

\section{References}

1. Hofer T (2003) Lichen striatus in adults or 'adult blaschkitis'?. There is no need for a new naming. Dermatology 207: 89-92. [Crossref]

2. Leung AK, Robson WL (2009) Lichen striatus. In: Lang F (Ed.), The Encyclopedia of Molecular Mechanisms of Disease. Berlin: Springer-Verlag, 1170-1171.

3. Gupta D, Mathes E (2015) Lichen striatus. In: Heyman WR, Anderson BE, Hivnor C, et al. (Eds.), Clinical Decision Support: Dermatology. Wilmington, Delaware: Decision Support in Medicine, LLC, 201 electronic database. URL:http://www. decisionsupportinmedicine.

4. Leung AK. Lichen striatus. In: Leung AK. (Ed.), Common Problems in Ambulatory Pediatrics: Specific Clinical Problems, volume 2. New York: Nova Science Publishers, Inc., 201: 267-270.

5. Karp DL, Cohen BA (1993) Onychodystrophy in lichen striatus. Pediatr Dermatol 10 359-361. [Crossref]

6. Fogagnolo L, Barreto JA, Soares CT, Marinho FC, Nassif PW (2011) Lichen striatus on adult. An Bras Dermatol 86: 142-145. [Crossref]

7. Amer A (2014) Bilateral onychodystrophy in a boy with a history of isolated lichen striatus. Cutis 94: E16-E19. [Crossref]

8. Racette AJ Adams AD, Kessler SE (2009) Simultaneous lichen striatus in siblings along the same Blaschko line. Pediatr Dermatol 26: 50-54. [Crossref]

9. Zhang Y, McNutt NS (2001) Lichen striatus. Histological, immunohistochemical, and ultrastructural study of 37 cases. J Cutan Pathol 28: 65-71. [Crossref]

10. Ishikawa M, Ohashi T, Yamamoto $\mathrm{T}$ (2014) Lichen striatus following influenza infection. J Dermatol 41: 1133-1134. [Crossref]

11. Lora V, Kanitakis J, Latini A, Cota C (2014) Lichen striatus associated with etanercept treatment of rheumatoid arthritis. J Am Acad Dermatol 70: e90-e92. [Crossref]

12. Unal E, Balta I, Bozkurt O (2014) Lichen striatus: after a bite by bumblebee. Cutan Ocul Toxicol 18:1-2. [Crossref]

13. Shepherd V, Lun K, Strutton G (2005) Lichen striatus in an adult following trauma. Australas J Dermatol 46: 25-28. [Crossref]

14. Mu EW, Abuav R, Cohen BA (2013) Facial lichen striatus in children: retracing the lines of Blaschko. Pediatr Dermatol 30: 364-366. [Crossref]

15. Pride H (2015) Lichen striatus. In: McMillan J, Barrett D, Boney C, (Eds.), Clinical Decision Support: Dermatology. Wilmington, Delaware: Decision Support in Medicine, LLC., 201 electronic database. URL:http://www.decisionsupportinmedicine.com

16. Goyal S, Cohen BA (2001) Pathological case of the month. Lichen striatus. Arch Pediatr Adolesc Med 155: 197-198. [Crossref] 
17. Sato H, Shirai A, Asahina A (2012) Case of lichen striatus presenting with multiple lesions along Blaschko's lines. J Dermatol 39: 802-804. [Crossref]
18. Campanati A, Brandozzi G, Giangiacomi M, Simonetti O, Marconi B, et al. (2008) Lichen striatus in adults and pimecrolimus: open, off-label clinical study. Int $J$ Dermatol 47: 732-736. [Crossref]

Copyright: $(02015$ Leung AKC. This is an open-access article distributed under the terms of the Creative Commons Attribution License, which permits unrestricted use, distribution, and reproduction in any medium, provided the original author and source are credited. 